This item was submitted to Loughborough's Research Repository by the author.

Items in Figshare are protected by copyright, with all rights reserved, unless otherwise indicated.

\title{
Is weight cycling associated with adverse health outcomes? A cohort study
}

PLEASE CITE THE PUBLISHED VERSION

https://doi.org/10.1016/j.ypmed.2017.12.010

\section{PUBLISHER}

(c) Elsevier

\section{VERSION}

AM (Accepted Manuscript)

\section{PUBLISHER STATEMENT}

This work is made available according to the conditions of the Creative Commons Attribution-NonCommercialNoDerivatives 4.0 International (CC BY-NC-ND 4.0) licence. Full details of this licence are available at: https://creativecommons.org/licenses/by-nc-nd/4.0/

\section{LICENCE}

CC BY-NC-ND 4.0

\section{REPOSITORY RECORD}

Madigan, Claire D., Toby Pavey, Amanda J. Daley, Kate Jolly, and Wendy J. Brown. 2019. "Is Weight Cycling Associated with Adverse Health Outcomes? A Cohort Study". figshare. https://hdl.handle.net/2134/32190. 


\section{Is weight cycling associated with adverse health outcomes? A cohort study}

Claire D Madigan ${ }^{1}$, Toby Pavey ${ }^{2,4}$, Amanda J Daley ${ }^{3}$, Kate Jolly ${ }^{3}$, Wendy J Brown ${ }^{4}$

${ }^{1}$ Nuffield Department of Primary Care Health Sciences, University of Oxford, Radcliffe

Primary Care, Radcliffe Observatory Quarter, Woodstock Road, Oxford, OX2 6GG.

${ }^{2}$ School of Exercise and Nutrition Sciences, Queensland University of Technology,

Queensland, Australia

${ }^{3}$ Institute of Applied Health Research, University of Birmingham, Edgbaston, Birmingham, B15 2TT, UK

${ }^{4}$ School of Human Movement and Nutrition Sciences, University of Queensland, Australia

Corresponding author: Claire Madigan

Email: claire.madigan@phc.ox.ac.uk

Phone: +441865 289340

Funding: This research analyses did not receive any specific grant from funding agencies in the public, commercial, or not-for-profit sectors. However the research on which this paper is based was conducted as part of the Australian Longitudinal Study on Women's Health, The University of Newcastle and The University of Queensland. We are grateful to the Australian Government Department of Health for funding.

Conflicts of interest: The authors declare they have no conflicts of interest.

Word count: 3942 


\section{Abstract (239 words)}

Evidence about the health effects of weight cycling is not consistent, with some studies suggesting it is harmful for health. Here we investigated whether weight cycling was associated with weight change and mental health outcomes in 10,428 participants in the midage cohort of The Australian Longitudinal Study of Women's Health (ALSWH) over 12 years. In 1998 the women were asked how many times they had ever intentionally lost at least $5 \mathrm{~kg}$ and how many times had they regained this amount. Women were categorised into four weight pattern groups: frequent weight cyclers ( $F W C$, three or more weight cycles), low frequency weight cyclers ( $L F W C$, one or two weight cycles), non-weight cyclers (NWC), and weight loss only $(W L)$. We used generalised linear modelling to investigate relationships between weight pattern group, weight change and mental health outcomes. In 1998, 15\% of the women were FWC, 24\% LFWC, 46\% NWC and 15\% were $W L$. Weight change was similar across weight pattern groups in women with obesity, however healthy weight and overweight FWC gained more weight than women who did not weight cycle. We found no difference in overall mental health scores between groups, but both $L F W C$ and FWC had higher odds of depressive symptoms (adjusted OR 1.5, 95\%CI: 1.1 to 1.9 and 1.7, 95\%CI: 1.1 to 2.4, respectively) than NWC. Our results suggest that, although weight cycling is not associated with greater weight gain in women with obesity, it may increase depressive symptoms.

Key words: weight loss, weight management, weight regain, weight cycling, health 


\section{Introduction}

The prevalence of overweight and obesity is concerning, with approximately $63 \%$ of the adult population of Australia classified as overweight or obese (Australian Bureau of Statistics, 2013). The consequences of excess weight include increased risks of developing type 2 diabetes, cardiovascular disease, musculoskeletal problems and many cancers, leading to premature death (Blissmer et al., 2006; Guh et al., 2009; Renehan, Tyson, Egger, Heller, \& Zwahlen, 2008). However losing at least 5\% of initial body weight is associated with improvements in glycaemic control, blood pressure, triglycerides and HDL cholesterol (Van Gaal, Mertens, \& Ballaux, 2005; Vidal, 2002; Wing \& Hill, 2001; Wing et al., 2011). For these reasons it is recommended that people who are classified as overweight and obese should lose weight, using effective weight loss interventions (Jebb et al., 2011; Jolly et al., 2011; LeBlanc, O’connor, Whitlock, Patnode, \& Kapka, 2011). However, while interventions can result in clinically meaningful weight loss, weight regain is common, due to a combination of low adherence to weight control strategies and compensatory physiological mechanisms that influence weight regain (Hartmann-Boyce et al., 2013; MacLean et al., 2015).

There are concerns that periods of intentional weight loss followed by unintentional weight gain, commonly described as weight cycling, are harmful for health (Lissner et al., 1991; Sørensen, Rissanen, Korkeila, \& Kaprio, 2005). Weight cycling has been associated with greater risk of mortality (Lissner et al., 1991), and increased risk of developing chronic diseases such as stroke, heart disease and diabetes (French et al., 1997) as well as increased risk of fractures (French et al., 1997; Søgaard, Meyer, Tonstad, Håheim, \& Holme, 2008). It is hypothesised that the harmful effects are caused by a reduction in lean mass during weight loss that is not regained when weight is regained, with adverse effects on metabolism (Beavers et al., 2011). However, a recent review concluded that the evidence that weight cycling is harmful for health is sparse (Mehta, Smith, Muhammad, \& Casazza, 2014). For example, some studies (Arnold, Newman, Cushman, Ding, \& Kritchevsky, 2010; French et al., 1997) did not take intention to lose weight into account. This is important because weight loss due to illness could confound the association with adverse health outcomes. It is therefore important to consider the intentionality of weight loss, and whether weight is regained. 
As the prevalence of obesity continues to increase, there may be more weight loss attempts, and therefore multiple cycles of weight loss and regain in adulthood. However, the prevalence of weight cycling in the general population is unclear. A cross sectional study in Finland found that $10 \%$ of women and $7 \%$ of men were classified as severe weight cyclers. In other words participants had lost $\geq 5 \mathrm{~kg}$ three times or more and regained the lost weight (Lahti-Koski, Männistö, Pietinen, \& Vartiainen, 2005). However participants were only questioned about the last ten years, so these proportions could be conservative.

Although research has investigated relationships between weight cycling and physical health outcomes, few studies have examined the mental health sequelae of weight cycling (Foster, Sarwer, \& Wadden, 1997). The Finnish study (above) found cross-sectional associations between weight cycling and poor mental health (Lahti-Koski et al., 2005), which may reflect feelings of demoralisation and failure when weight is regained (Markowitz, Friedman, \& Arent, 2008).

As women are more likely than men to report attempts at weight loss (Green et al., 1997; Thompson \& Thomas, 2000), in this study we used data from the Australian Longitudinal Study of Women's Health (ALSWH) to examine: (1) the prevalence of weight cycling; (2) the characteristics of women who weight cycle, and of those with other weight patterns; and (3) whether weight cycling is associated with weight gain and mental health outcomes 12 years after reporting weight cycling.

\section{Methods}

The ALSWH is a prospective study of factors shaping the health and well-being of three cohorts of Australian women (born in 1973-1978, 1946-1951, and 1921-1926), recruited from the national health insurance database. The focus of this paper is on the 1946-1951 cohort who completed mailed surveys in 1996, 1998, 2001, 2004, 2007 and 2010. Women were aged 47-52 years in 1998 when data on the main variable of interest (weight cycling) were collected. More details can be found at the study website (Australian Longitudinal Study of Womens Health, 2017). The study was approved by the Universities of Newcastle and Queensland Ethical Review Committees and all participating women provided informed consent. 


\section{Exposure variable}

As there is no standardised definition of weight cycling, initial exploratory analyses were undertaken using responses from the following two questions: women were asked how many times (excluding pregnancy) had they ever lost $5 \mathrm{~kg}$ or more on purpose, and how many times they had ever gained $5 \mathrm{~kg}$ or more, which was previously lost on purpose. Responses (never, 1-2, 3-4, 5+ times) for each question were cross-tabulated and the number in each category was computed. Data from women who reported gaining $5 \mathrm{~kg}$ and never losing weight were removed from the analyses as the question asked how many times they had regained $5 \mathrm{~kg}$ that was previously lost on purpose ( $\mathrm{n}=307,3 \%$ of the sample). Based on a previous study that examined the prevalence of weight cycling (Lahti-Koski et al., 2005), responses were used to create the following weight cycling pattern categories:

- Non-weight cyclers (NWC): Women who reported having never lost or gained $5 \mathrm{~kg}$ of weight.

- Weight losers $(W L)$ : Women who reported losing $5 \mathrm{~kg}$ of weight and not regaining $5 \mathrm{~kg}$ of weight.

- Low frequency weight cyclers ( $L F W C$ ): Women who reported losing $5 \mathrm{~kg} 1-2$ times and regaining $5 \mathrm{~kg} \mathrm{1-2} \mathrm{times,} \mathrm{and} \mathrm{women} \mathrm{who} \mathrm{reported} \mathrm{losing} \mathrm{weight} \mathrm{three} \mathrm{times} \mathrm{or} \mathrm{more} \mathrm{but}$ only regaining weight $1-2$ times.

- Frequent weight cyclers (FWC): Those who reported losing $5 \mathrm{~kg}$ three or more times and regaining $5 \mathrm{~kg}$ three or more times.

\section{Outcome variables}

All three-outcome measures were assessed in 1998 and in 2010, with weight change calculated as the difference between weights reported in these two years. Weight (to the nearest kg) was reported at each survey. Health related quality of life (HRQL) was measured using the well-validated Medical Outcomes Study's Health Status survey short-form 36 (SF36) (Ware JE, Kosinski M, \& Keller SD, 1994). Four subscales (14 items) measure psychological HRQL: vitality, social functioning, mental health and role limitations from emotional problems. The mental health component summary score (MCSS), with factor structures validated using baseline ALSWH surveys, was used as a summary measure of theses scales. Scores were standardized to range from $0-100$, with the mean set at 50 , with 
higher scores indicating more positive psychological well-being (Mishra \& Schofield, 1998). Change in MCSS was the difference in MCSS in 1998 and 2010. The Center for Epidemiologic Studies Depression Scale (CESD-10) was used to measure depressive symptoms in 1998 and 2010, with scores $\geq 10$ indicating depressive symptoms (Andresen, Malmgren, Carter, \& Patrick, 1994).

\section{Potential Confounders}

Socio-demographic (partnership status, parity), behavioural (smoking, alcohol use, physical activity, use of laxatives, diuretics or diet pills) and health related variables (BMI, use of hormone replacement therapy (HRT), age at menopause, and an indicator of overall physical health, (the physical components summary score of the SF36, PCSS)), which were indicated by previous work to be associated with either weight patterning group, weight change or psychological well-being, were selected as potential confounders. Data for all these variables were from the 1998 survey, except parity, which was only measured in 1996. The variables were categorised as shown in Table 1.

BMI was calculated as weight $(\mathrm{kg}) /$ height $^{2}\left(\mathrm{~m}^{2}\right)$, physical activity was assessed using questions developed for national surveillance of physical activity in Australia (Armstrong, Bauman, \& Davies, 2000; Brown, Burton, Marshall, \& Miller, 2008), and women were categorised as meeting the minimal recommended amount of physical activity (500 MET $\mathrm{min} /$ week) or not. Women were asked whether they had used laxatives, diuretics or diet pills to control their weight as an indication of disordered eating.

\section{Descriptive Data}

Prevalence of chronic conditions was based on responses to a question that asked whether a doctor had diagnosed any of the obesity-related conditions shown in Table 1. Information about education, area of residence and age first dieted are reported.

\section{Statistical analysis}

Analyses were conducted in September 2017. There were 12,388 women who completed the 1998 survey. Women were excluded if they had missing data needed to create the weight pattern variable $(n=1960)$. Therefore data from 10,428 women were included in the descriptive analyses; 7512 of these women provided full data for all variables in the model for the predictive analysis of weight change. For the other health outcomes, data were 
available for 7,435 (MCSS) and 7,259 (CESD-10 depression scores) women. Baseline characteristics were summarised using descriptive statistics. Initial analyses (using $\mathrm{Chi}^{2}$, ANOVA and Pearson's correlations) were completed to assess whether each potential confounder was associated $(\mathrm{p}<0.05)$ with both the independent (weight pattern group) and each of the dependent variables (weight change or MCSS or CESD-10 score $\geq 10$ ).

Variables which met this criterion were included as confounders in each model as follows:

Weight change: smoking, BMI and PCSS

MCSS: alcohol consumption, physical activity, BMI and PCSS

CESD-10: physical activity, smoking, alcohol consumption, BMI, PCSS and use of diuretics, laxatives or diet pills

\section{Weight change and Mental Health Component Outcomes}

Generalised Linear Modelling was used to explore the relationships between weight pattern group, with weight change and with mental health. For both models, BMI was included as an interaction term, with confounders added as stated above. If the interaction of BMI was significant then estimates of mean changes and pairwise comparisons were made by BMI category and weight pattern group. As BMI was a significant interaction term for the weight change model, results are firstly reported as mean weight change within BMI category. Then we report comparisons of mean differences in weight change between the $N W C$ and the other weight pattern groups by BMI category with associated 95\% confidence intervals. This allows us to compare BMI categories with different weight pattern groups e.g. obese NWC vs. obese FWC. BMI did not have a significant interaction in either of the mental health analyses. Results are reported as differences in mean MCSS change between the NWC (reference group) and other weight pattern groups, with associated 95\% confidence intervals.

\section{CESD-10 outcomes}

Logistic generalised linear modelling was used to examine the association between weight pattern groups and CESD-10 scores (reference CESD $\leq 10$ ). The same methods as above were used to identify the confounders for the model. Results are reported as odd ratios with 95\% confidence intervals. 
All statistical analyses were conducted in SPSS version 24. P-values were based on two-sided tests and were considered statistically significant at $\mathrm{P}<0.05$.

\section{Results}

In 1998 the women were on average 49.5 (Standard Deviation [SD] 1.5) years of age, with a BMI of 26.3 (SD 5.4) kg/m². Fewer than half had never lost or gained $5 \mathrm{~kg}$ (NWC) and about one in seven reported losing $5 \mathrm{~kg}$ and never regaining this $(W L)$. Almost one quarter of the women had either lost or gained $5 \mathrm{~kg}$ once or twice ( $L F W C$ ), and about one in six had both lost and gained $5 \mathrm{~kg}$ three times or more (FWC) (See Table 1).

The women's demographic, behavioural and health characteristics are shown in Table 1. The majority of the women had completed high school education, had at least one birth and lived in rural areas (due to intentional over-sampling of rural women for the ALSWH study). Approximately 55\% had never smoked and the majority were low risk drinkers. Forty per cent met recommended physical activity levels. The most common health condition was hypertension (18.9\%); prevalence of the other conditions was less than $4 \%$.

\section{Baseline characteristics}

Women in the FWC group were more likely to be ex-smokers, and had started dieting at a younger age (at least six years earlier) than women in the NWC group (See Table 1). Average BMI was higher in the FWC group, and a greater proportion was obese. In 1998 the proportion of women with poor mental health scores was greater in women classified as FWC than in the other groups. There were similar patterns for CESD-10 scores. In 1998 FWC women also had poorer physical function scores, and were more likely to report using diuretics, laxatives or diet pills to control their weight, and to have diabetes and hypertension, than the NWC.

\section{Weight change}

Average weight changes in each weight pattern group are shown in Table 2. The overall average weight gain was $3.6 \mathrm{~kg}$ (SD 8.1) over 12 years. Weight gain was highest in the $W L$ group and lowest in the FWC group, although the differences were small (Table 2). As BMI category was a significant $(\mathrm{p}=<0.001)$ interaction term, we examined these results within BMI category (Table 3). The results for the underweight group are not discussed further as 
the numbers were too small to produce reliable estimates of weight change for each weight pattern group. For women with obesity, weight gain ranged from 0.8 to $2.5 \mathrm{~kg}$ with the FWC group gaining the least amount of weight. Overweight women gained more weight than women with obesity. The NWC women gained the least weight and the $W L$ group gained the most within this BMI category. Women with healthy weight gained a similar amount of weight to overweight women, and within this category $N W C$ women gained the least and the FWC women gained the most weight.

As BMI category was an important factor in the effect of weight cycling on weight change, we compared mean differences in weight change between the NWC and other weight pattern groups, within BMI categories (Table 4). For women with obesity there was no difference in weight change between FWC and NWC. However healthy weight or overweight women who were FWC gained more weight than women with the same respective BMI categories in the NWC group. Across the BMI categories, the LFWC gained more weight than NWC. Similar to FWC with obesity, the $W L$ women with obesity gained similar amounts of weight to the $N W C$. There were no differences in weight change between overweight $W L$ women and $N W C$ women. However healthy weight $W L$ women gained more weight than the $N W C$ women in this BMI category.

\section{Mental health}

Changes in MCSS are shown in Table 2. Overall, MCSS improved over 12 years, from 47.8 in 1998 to 50.5 in 2012. After adjusting for covariates, there were no significant indications of differences between the groups. The increase in MCSS scores was slightly higher in the FWC group than in the NWC group; this is however likely to reflect the lower baseline values in the FWC group. Changes in CESD scores are also shown in Table 2. The odds for depressive symptoms were higher in both the $L F W C$ and FWC groups at 12 years follow-up, than in the NWC.

\section{Discussion}

Summary of results

Almost $40 \%$ of the women in this sample reported a history of weight cycling, of which $15 \%$ were classified as frequent weight cyclers. This group were much more likely to be obese; 
reported starting dieting at a younger age and were more likely to have used laxatives, diuretics and diet pills, than the women who had never weight cycled.

Our results showed that long-term weight gain was higher among women who frequently weight cycled, but this was only observed in healthy weight and overweight women. Weight cycling was not harmful with regards to weight gain for FWC women with obesity. Weight cycling was associated with poorer mental health at baseline and higher odds of depressive symptoms after 12 years of follow up.

\section{Comparison with similar studies}

The prevalence of weight cycling was marginally higher (by 5\%) in this study than in a cross sectional Finnish study that reported a prevalence of between 7 and $10 \%$ for weight cycling, using the same definition as we did (Lahti-Koski et al., 2005). This is likely because the Finnish study asked about the last ten years, whereas in our study we asked the women if they had ever lost and gained weight. The Finnish study also included men and a greater age range, which may explain some differences. The Finnish study also found associations between poorer health and weight cycling. We found similar findings at baseline, in that women classified as FWC had greater prevalence of diabetes and hypertension, poorer general mental health scores and higher depressive symptoms than NWC.

As far as we are aware, no studies have examined weight change and mental health outcomes over time by weight pattern group, in the same way that we did. However, other researchers have shown, in a randomised trial, that a history of weight cycling did not impede future weight loss or metabolism over 12 months (Mason et al., 2013). This supports our findings that women with obesity gained similar amounts of weight, regardless of their weight pattern. These results are not directly comparable, as the women in the ALSWH study on average gained weight, and there was no intervention for weight loss. In their cohort study, the Prospective Studies Collaboration did not investigate weight cycling, but they found that there was a smaller increase in BMI over 13 years in those with BMI greater than $30 \mathrm{~kg} / \mathrm{m}^{2}$ than in those with BMI $<30 \mathrm{~kg} / \mathrm{m}^{2}$ at baseline (Prospective Studies Collaboration, 2009). This was similar to our findings, in that women with obesity gained less weight than women in the other BMI categories.

Another related study which defined weight cyclers as those that had lost $\geq 2.3 \mathrm{~kg}$ on five or more occasions, found that $49 \%$ of women and $52 \%$ of men were weight cyclers (Van Wye, 
Dubin, Blair, \& Di Pietro, 2007). This higher prevalence can be explained by the low weight change criteria, compared with those used in this study. In that study women were on an average a healthy weight and men were overweight. In contrast to our study there was no significant difference in weight gain between weight cyclers and non-weight cyclers. Yet another study found that weight cycling (prevalence 4.1\%) in the previous two years (defined as intentionally losing $5 \mathrm{~kg}$ and unintentionally gaining $5 \mathrm{~kg}$ ) was associated with greater odds of weight gain (Kroke et al., 2002). However this study had a short follow-up of only two years.

Similar to our findings, the Nurses Health Study has shown that women who were obese at baseline had higher odds of depression at follow-up (OR 1.11, 95\% CI, 1.03-1.18) (Pan et al., 2012) but the relationship between weight cycling and mental health outcomes was not investigated. The Nurses Health Study suggested that the act of controlling weight could be more stressful than being obese, and that, if women have unsuccessful weight loss attempts this may lead to greater depressive symptoms. However it could also be that depressive symptoms could lead to weight gain over time.

To summarise, the overall evidence suggests that for people with obesity there is no association between weight cycling and weight gain. As periods of time being at a lower weight are likely to be beneficial for other markers of health, such as blood glucose, blood pressure and lipids, weight loss should be encouraged, even if weight is regained (Wing et al., 2011). In the healthy weight and overweight categories, FWC women gained more weight than NWC women. This may reflect that $F W C$ women were struggling to maintain their weight, or their use of unhealthier weight management practices (i.e. laxatives etc) which may eventually result in greater weight gain (Madigan, Daley, Kabir, Aveyard, \& Brown, 2015). As physical activity is known to assist with both prevention and management of weight gain and depressive symptoms, encouraging physical activity should be a cornerstone of weight management advice and given as advice to women.

\section{Strengths and Limitations}

The strengths of this study include the large representative sample of mid-aged women, the longitudinal study design, and the long follow up period. Data were examined by BMI category, which allowed further exploration of weight cycling. In the future we may have prospective objective measures of weight, through smart scales, which could provide regular 
weights to enable us to precisely measure periods of weight loss and weight gain. However, in the meantime, weight cycling studies rely on self-reported weight losses and regain. Women were asked about their weight cycling in 1998 and were followed up over 12 years. As the prevalence of obesity has increased, it is likely that the prevalence of weight cycling is also higher now, but the weight cycling questions were not included in subsequent surveys, so we could not identify whether women continued to weight cycle during the follow-up period.

The study was not without limitations. Although there is no consensus on the definition of weight cycling, to allow comparison we used a definition that has been used by others (LahtiKoski et al., 2005). This may have been conservative, because a more sensitive dose-response investigation (with more categories of cycling frequency) together with measures of the rate of weight loss/gain could be associated with health outcomes. However, as our surveys were conducted every three years, these issues could not be investigated here. Another limitation is that we relied on self-reported data. A validation study with a subsample of the ALSWH mid age cohort has shown good agreement between self-reported and measured weight (Burton, Brown, \& Dobson, 2010). However, bias in terms of under reporting weight is higher in obese women - but as long as each woman under or over reports weight in the same way each time, then weight change is not affected. As in all cohort studies, there were some missing data.

To overcome some of these limitations future research could use electronic objective scales that record data in real time to objectively identify periods of weight cycling and further examine the dose response relationships between weight cycling and future weight loss and gain. It would also be interesting to further explore weight cycling in healthy weight women, particularly the reasons why these women weight cycle and the practices they use to manage their weight. Additionally, as far as we are aware, no other analyses have investigated weight cycling and weight change by BMI, therefore this could be repeated in other cohorts to confirm findings.

\section{Conclusions}

The effects of weight cycling in healthy weight and overweight women are complex, and require further exploration, but our findings suggest that weight cycling is associated with weight gain in these groups. Although this was not the case for women with obesity who gained 
similar amounts of weight independent of BMI category. Weight cycling was associated with depressive symptoms. This may reflect a perception of 'failure' to control weight. Designers of weight management programmes should take this into account when developing interventions. In particular they might consider counselling women about the likelihood of weight regain and reframe weight regain from being a sign of failure to a signal that they need to commence strategies to get back to controlling their weight. Physical activity should also be encouraged to help with weight maintenance and depressive symptoms.

\section{Acknowledgements}

The research on which this paper is based was conducted as part of the Australian Longitudinal Study on Women's Health, The University of Newcastle and The University of Queensland. We are grateful to the Australian Government Department of Health for funding and to the women who provided the survey data. Kate Jolly is supported by the NIHR Collaborations for Leadership in Applied Health Research and Care West Midlands initiative. This paper presents independent research and the views expressed are those of the authors and not necessarily those of the NHS, the NIHR or the Department of Health. Thank you to Alecia Nickless for advice regarding the analyses and Dr Jeremy Howick for reading an earlier script. 


\section{References}

Andresen, E., Malmgren, J., Carter, W., \& Patrick, D. (1994). Screening for depression in well older adults: evaluation of a short form of the CES-D (Center for Epidemiologic Studies Depression Scale). American journal of preventive medicine, 10, 77-84.

Armstrong, T., Bauman, A., \& Davies, J. (2000). Physical activity patterns of Australian adults. Results of the 1999 National Physical Activity Survey. Retrieved from Canberra:

Arnold, A., Newman, A., Cushman, M., Ding, J., \& Kritchevsky, S. (2010). Body Weight Dynamics and Their Association With Physical Function and Mortality in Older Adults: The Cardiovascular Health Study. The Journals of Gerontology Series A: Biological Sciences and Medical Sciences, 65A(1), 63-70. doi:10.1093/gerona/glp050

Australian Bureau of Statistics. (2013). Australian Health Survey: updated results, 20112012. Retrieved from Canberra:

Australian Longitudinal Study of Womens Health. (2017). Study Overview. Retrieved from http://www.alswh.org.au

Beavers, K. M., Lyles, M., Davis, C., Wang, X., Beavers, D., \& Nicklas, B. (2011). Is lost lean mass from intentional weight loss recovered during weight regain in postmenopausal women? American Journal of Clinical Nutrition, 94(3), 767-774. doi:10.3945/ajcn.110.004895

Blissmer, B., Riebe, D., Dye, G., Ruggiero, L., Greene, G., \& Caldwell, M. (2006). Healthrelated quality of life following a clinical weight loss intervention among overweight and obese adults: intervention and 24 month follow-up effects. Health Quality Life Outcomes, 4, 43. doi:10.1186/1477-7525-4-43

Brown, W., Burton, N., Marshall, A., \& Miller, Y. (2008). Reliability and validity of a modified self administered version of the Active Australia physical activity survey in a sample of mid-age women. Aust N Z J Public Health, 32(6), 535-541. doi:10.1111/j.1753-6405.2008.00305.x

Burton, N., Brown, W., \& Dobson, A. (2010). Accuracy of body mass index estimated from self reported height and weight in mid- aged Australian women. Australian and New Zealand Journal of Public Health, 34(6), 620-623. doi:10.1111/j.17536405.2010.00618.x

Foster, G. D., Sarwer, D. D., \& Wadden, T. A. (1997). Psychological Effects of Weight Cycling in Obese Persons: A Review and Research Agenda. Obesity, 5(5), 474-488. doi:10.1002/j.1550-8528.1997.tb00674.x 
French, S., Folsom, A., Jeffery, R., Zheng, W., Mink, P., \& Baxter, J. (1997). Weight variablity and incident of disease in older women: the IOWA women's health study. International Journal of Obesity, 21, 217-223.

Green, K., Cameron, R., Polivy, J., Cooper, K., Liu, L., Leiter, L., . . Canadian Heart Health Surveys Research Group. (1997). Weight dissatisfaction and weight loss attempts among Canadian adults. Can Med Assoc, 157 (suppl 1).

Guh, D., Zhang, W., Bansback, N., Amarsi, Z., Birmingham, C., \& Anis, A. (2009). The incidence of comorbidities related to obesity and overweight: a systematic review and meta-analysis. Bmc Public Health, 9(88). doi:10.1186/1471-2458-9-88

Hartmann-Boyce, J., Johns, D., Aveyard, P., Onakpoya, I., Jebb, S., Phillips, D., . . . Summerbell, C. (2013). Managing overweight and obese adults: update review. Retrieved from http://www.nice.org.uk/nicemedia/live/14530/67812/67812.pdf

Jebb, S. A., Ahern, A. L., Olson, A. D., Aston, L. M., Holzapfel, C., Stoll, J., . . Caterson, I. D. (2011). Primary care referral to a commercial provider for weight loss treatment versus standard care: a randomised controlled trial. Lancet, 378, 1485-1492. doi:http://dx.doi.org/10.1016/S0140-6736(11)61344-5

Jolly, K., Lewis, A., Beach, J., Denley, J., Adab, P., Deeks, J. J., . . Aveyard, P. (2011). Comparison of range of commercial or primary care led weight reduction programmes with minimal intervention control for weight loss in obesity: Lighten Up randomised controlled trial. BMJ, 343. doi:10.1136/bmj.d6500

Kroke, A., Liese, A., Schulz, M., Bergmann, M., Klipstein-Grobusch, K., Hoffmann, K., \& Boeing, H. (2002). Recent weight changes and weight cycling as predictors of subsequent two year weight change in amiddle-aged cohort. International Journal of Obesity, 26, 403-409. doi:10.1038/sj.ijo.0801920

Lahti-Koski, M., Männistö, S., Pietinen, P., \& Vartiainen, E. (2005). Prevalence of weight cycling and its relation to health indicators in Finland. Obesity Research, 13(2), 333341. doi:10.1038/oby.2005.45

LeBlanc, E., O’connor, E., Whitlock, E., Patnode, C., \& Kapka, T. (2011). Effectiveness of Primary Care - Relevant Treatments for Obesity in Adults: A Systematic Review for the US Preventive Services Task Force Annals of Internal Medicine, 155(7), 434-447. doi:10.7326/0003-4819-155-7-201110040-00006

Lissner, L., Odell, P. M., D'Agostino, R. B., Stokes, J., Kreger, B. E., Belanger, A. J., \& Brownell, K. D. (1991). Variability of Body Weight and Health Outcomes in the Framingham Population. New England Journal of Medicine, 324(26), 1839-1844. doi:10.1056/NEJM199106273242602 
MacLean, P., Wing, R., Davidson, T., Epstein, L., Goodpaster, B., Hall, K., . . . Ryan, D. (2015). NIH working group report: Innovative research to improve maintenance of weight loss. Obesity, 23(1), 7-15. doi:10.1002/oby.20967

Madigan, C. D., Daley, A. J., Kabir, E., Aveyard, P., \& Brown, W. J. (2015). Cluster analysis of behavioural weight management strategies and associations with weight change in young women: a longitudinal analysis. Interntational Journal of Obesity, 39, 16011606. doi:10.1038/ijo.2015.116

Markowitz, S., Friedman, M. A., \& Arent, S. (2008). Understanding the Relation Between Obesity and Depression: Causal Mechanisms and Implications for Treatment. Clinical Psychology Science and Practice, 15, 1-20. doi:10.1111/j.1468-2850.2008.00106.x

Mason, C., Foster-Schubert, K., Imayama, I., Xiao, L., Kong, A., Campbell, K., . . . McTiernan, A. (2013). History of weight cycling does not impede future weight loss or metabolic improvements in postmenopausal women. Metabolism, 62(1), 127-136. doi:10.1016/j.metabol.2012.06.012

Mehta, T., Smith, D. L., Muhammad, J., \& Casazza, K. (2014). Impact of weight cycling on risk of morbidity and mortality. Obesity Reviews, 15(11), 870-881. doi:10.1111/obr.12222

Mishra, G., \& Schofield, D. (1998). Norms for physical and mental health component summary scores for young, middle and older Australian women. Quality of Life Research, 7(3), 215-220.

Pan, A., Sun, Q., Czernichow, S., Kivimaki, M., Okereke, O., Lucas, M., \& Hu, F. (2012). Bidirectional Association between Depression and Obesity in Middle-aged and Older Women. International Journal of Obesity, 36(4), 595-602. doi:http://doi.org/10.1038/ijo.2011.111

Prospective Studies Collaboration. (2009). Body-mass index and cause-specific mortality in 900000 adults: collaborative analyses of 57 prospective studies. Lancet, 373, 19831996. doi:http://dx.doi.org/10.1016/S0140-6736(09)60318-4

Renehan, A., Tyson, M., Egger, M., Heller, R., \& Zwahlen, M. (2008). Body-mass index and incidence of cancer: a systematic review and meta-analysis of prospective observational studies. Lancet, 371, 569-570. doi:10.1016/S0140-6736(08)60269-X

Søgaard, A., Meyer, H., Tonstad, S., Håheim, L., \& Holme, I. (2008). Weight Cycling and Risk of Forearm Fractures: A 28-Year Follow-up of Men in the Oslo Study. American Journal of Epidemiology, 167(8), 1005-1013. doi:10.1093/aje/kwm384 
Sørensen, T., Rissanen, A., Korkeila, M., \& Kaprio, J. (2005). Intention to Lose Weight, Weight Changes, and 18-y Mortality in Overweight Individuals without CoMorbidities. Plos Medicine, 2(6), e171. doi:10.1371/journal.pmed.0020171

Thompson, R., \& Thomas, D. (2000). A cross-sectional survey of the opinions on weight loss treatments of adult obese patients attending a dietetic clinic. Int J Obes Relat Metab Disord, 24(2), 164-170.

Van Gaal, L., Mertens, I., \& Ballaux, D. (2005). What is the relationship between risk factor reduction and degree of weight loss? European Heart Journal Supplement, 7, L21L26. doi:https://doi.org/10.1093/eurheartj/sui082

Van Wye, G., Dubin, J. A., Blair, S. N., \& Di Pietro, L. (2007). Weight Cycling and 6-Year Weight Change in Healthy Adults: The Aerobics Center Longitudinal Study. Obesity, 15(3), 731-739.

Vidal, J. (2002). Updated review on the benefits of weight loss. International Journal of Obesity Related Metabolic Disorders, 26(Supplement 4), S25-S28. doi:10.1038/sj.ijo.802215

Ware JE, Kosinski M, \& Keller SD. (1994). SF-36 Physical and Mental Health Summary Scales: A users manual. Retrieved from Boston:

Wing, R., \& Hill, J. (2001). Successful weight loss maintenance. Annual Review of Nutrition, 21, 323-341. doi:10.1146/annurev.nutr.21.1.323

Wing, R., Lang, W., Wadden, T., Safford, M., Knowler, W., Bertoni, A., .. . Group, L. A. R. (2011). Benefits of Modest Weight Loss in Improving Cardiovascular Risk Factors in Overweight and Obese Individuals with Type 2 Diabetes. Diabetes Care, 34, 14811486. 
Table 1: Demographic, behavioural and health characteristics of the women in each weight pattern group in $1998^{*}(N(\%)$ unless stated)

\begin{tabular}{|c|c|c|c|c|}
\hline & $\begin{array}{c}N W C \\
n=4820(46.2 \%)\end{array}$ & $\begin{array}{c}W L \\
n=1540(14.8 \%)\end{array}$ & $\begin{array}{c}\text { LFWC } \\
n=2465(23.6 \%)\end{array}$ & $\begin{array}{c}F C \\
n=1603(15.4 \%)\end{array}$ \\
\hline \multicolumn{5}{|c|}{ Demographic variables } \\
\hline \multicolumn{5}{|l|}{ Education } \\
\hline High school or less & $3197(66.3)$ & $989(64.2)$ & 1577 (64.0.) & $979(61.1)$ \\
\hline Diploma/ apprenticeship & $893(18.5)$ & $310(20.1)$ & 539 (21.9) & $332(20.7)$ \\
\hline Degree/ higher degree & $694(14.4)$ & $229(14.9)$ & $333(13.5)$ & $275(17.2)$ \\
\hline Missing & $36(0.7)$ & $12(0.8)$ & $16(0.6)$ & $17(1.1)$ \\
\hline \multicolumn{5}{|l|}{ Parity } \\
\hline At least one birth & $4202(87.2)$ & $1359(88.2)$ & $2160(87.6)$ & $1411(88.0)$ \\
\hline Missing & $270(5.6)$ & $67(4.4)$ & $102(4.1)$ & $59(3.7)$ \\
\hline \multicolumn{5}{|l|}{ Marital status } \\
\hline Partnered & $3983(82.6)$ & $1277(82.9)$ & $2053(83.3)$ & $1301(81.2)$ \\
\hline Missing & $39(0.8)$ & $9(0.6)$ & $8(0.3)$ & $5(0.3)$ \\
\hline \multicolumn{5}{|c|}{ Behavioural variables } \\
\hline \multicolumn{5}{|l|}{ Smoking status } \\
\hline Never smoked & $2836(58.8)$ & $848(55.1)$ & $1334(54.1)$ & $830(51.8)$ \\
\hline Ex-smoker & $1052(21.8)$ & $457(29.7)$ & $734(29.8)$ & 543 (33.9) \\
\hline Smoker & $901(18.7)$ & $227(14.7)$ & $387(15.7)$ & $224(14.0)$ \\
\hline Missing & $31(0.6)$ & $8(0.5)$ & $10(0.4)$ & $6(0.4)$ \\
\hline \multicolumn{5}{|l|}{ Physical Activity } \\
\hline $\begin{array}{l}\text { Meeting } \\
\text { recommendations }\end{array}$ & $2625(54.5)$ & $913(59.3)$ & $1406(57.0)$ & $877(54.7)$ \\
\hline Missing & $185(3.8)$ & $46(3.0)$ & $51(2.1)$ & $37(2.3)$ \\
\hline \multicolumn{5}{|l|}{ Alcohol } \\
\hline Low risk & $3829(79.5)$ & $2786(81.4)$ & $2021(82.0)$ & 1306 (81.9) \\
\hline Non-drinker & $690(14.3)$ & $186(12.1)$ & $276(11.2))$ & $193(12.0)$ \\
\hline Risky/high drinker & $254(5.3)$ & $93(6.0)$ & $153(6.2)$ & $96(6.0)$ \\
\hline Missing & $47(1.0)$ & $8(0.5)$ & $15(0.6)$ & $8(0.5)$ \\
\hline Age first dieted & $31.0(11.6)$ & $29.1(10.8)$ & $29.5(10.1)$ & $23.2(8.1)$ \\
\hline $\begin{array}{l}\text { Used laxatives, diuretics or } \\
\text { diet pills to control weight }\end{array}$ & $221(4.6)$ & $214(13.9)$ & $371(15.0)$ & $504(31.4)$ \\
\hline \multicolumn{5}{|c|}{ Health variables } \\
\hline $\begin{array}{l}\text { Mean BMI kg/m² (SD) } \\
\text { BMI Categories }\end{array}$ & $24.1(4.1)$ & $26.3(5.1)$ & $27.9(5.2)$ & $30.5(5.8)$ \\
\hline
\end{tabular}




\begin{tabular}{|c|c|c|c|c|}
\hline Underweight & $127(2.6)$ & $13(0.8)$ & $14(0.6)$ & $1(0.1)$ \\
\hline Healthy weight & $2892(60.0)$ & $692(44.9)$ & $712(28.9)$ & $237(14.8)$ \\
\hline Overweight & $1058(22.0)$ & $474(30.8)$ & $937(38.0)$ & $568(35.4)$ \\
\hline Obese & $376(7.8)$ & $281(18.2)$ & $653(26.5)$ & $698(43.5)$ \\
\hline Missing & $367(0.6)$ & $80(5.2)$ & $149(6.0)$ & $99(6.2)$ \\
\hline \multicolumn{5}{|l|}{$\begin{array}{l}\text { Prevalence of chronic } \\
\text { conditions }\end{array}$} \\
\hline Diabetes & $118(2.4)$ & $58(3.7)$ & $87(3.5)$ & $75(4.6)$ \\
\hline Heart Disease & $88(1.8)$ & $26(1.7)$ & $62(2.5)$ & $46(2.9)$ \\
\hline Thrombosis & $157(3.3)$ & $58(3.8)$ & $99(4.0)$ & $61(3.8)$ \\
\hline Stroke & $34(0.7)$ & $14(0.9)$ & $21(0.9)$ & $13(0.8)$ \\
\hline Hypertension & $695(14.4)$ & $320(20.8)$ & $523(21.2)$ & $430(26.8)$ \\
\hline Breast cancer & $124(2.6)$ & $30(1.9)$ & $56(2.3)$ & $27(1.7)$ \\
\hline \multicolumn{5}{|l|}{ CESD } \\
\hline score $>10$ & $1016(21.1)$ & $339(22.0)$ & $554(22.5)$ & $486(30.3)$ \\
\hline missing & $97(2.0)$ & $28(1.8)$ & $31(1.3)$ & $25(1.6)$ \\
\hline \multicolumn{5}{|l|}{ SF36 mean (SD) } \\
\hline $\begin{array}{l}\text { Mental health } \\
\text { component score }\end{array}$ & $48.2(12.1)$ & $48.4(12.4)$ & $47.9(12.0)$ & $45.8(13.3)$ \\
\hline $\begin{array}{l}\text { Physical health } \\
\text { component score }\end{array}$ & $49.6(9.2)$ & $49.4(9.4)$ & $48.6(9.2)$ & $47.6(9.8)$ \\
\hline HRT use at baseline & $1075(22.3)$ & $341(22.1)$ & $574(23.3)$ & $366(22.8)$ \\
\hline HRT use at survey 6 & $535(11.1)$ & $171(11.1)$ & $285(11.6)$ & $184(11.5)$ \\
\hline $\begin{array}{l}\text { Age at menopause } \\
\text { mean (SD) }\end{array}$ & $51.0(4.6)$ & $51.1(4.8)$ & $51.0(4.9)$ & $51.1(4.9)$ \\
\hline
\end{tabular}

NWC= non weight cyclers, WL = weight losers, LWC= low weight cyclers, FWC= frequent weight cyclers HRT $=$ hormone replacement therapy, BMI = body mass index, CESD-10 = Centre for Epidemiological depression scale, SF36 = MOS 36 item short form survey.

*Except education and parity which were only assessed in 1996 
Table 2: Changes in weight and mental health (1998 to 2010) and odds of depressive symptoms in 2010, by weight pattern group

\begin{tabular}{|c|c|c|c|c|}
\hline & NWC & $W L$ & LFWC & FWC \\
\hline \multicolumn{5}{|c|}{ Weight change mean (SD) } \\
\hline Weight in 1998 kg & $63.5(10.7)$ & $69.2(13.4)$ & $73.6(13.7)$ & $81.2(15.8)$ \\
\hline Weight in 2010 kg & $66.9(12.1)$ & $73.5(15.1)$ & $77.4(14.9)$ & $84.0(17.1)$ \\
\hline Weight change kg & $3.4(6.9)$ & $4.3(8.6)$ & $3.9(8.3)$ & $2.8(10.6)$ \\
\hline \multicolumn{5}{|c|}{ Mental health component scores mean (SD) } \\
\hline Mental Health Component Score 1998 & $48.2(12.1)$ & $48.4(12.4)$ & $47.9(12.0)$ & $45.8(13.3)$ \\
\hline Mental Health Component Score 2010 & $51.3(10.8)$ & $50.8(11.6)$ & $50.2(11.8)$ & $49.1(12.5)$ \\
\hline Change in MCSS mean (SD) & $2.8(11.4)$ & $1.9(12.3)$ & $1.8(11.8)$ & $2.8(12.9)$ \\
\hline $\begin{array}{l}\text { Mean difference in change scores } \\
\text { between the weight pattern groups } \\
\text { (adjusted) mean }(95 \% \mathrm{Cl})^{*}\end{array}$ & $\begin{array}{l}\text { Reference } \\
\text { group }\end{array}$ & $-0.1(-1.2$ to 1.0$)$ & $-1.0(-2.0$ to 0.1$)$ & $1.5(-0.3$ to 3.2$)$ \\
\hline \multicolumn{5}{|c|}{ CESD-10 } \\
\hline CESD-10 >10 $1998 \mathrm{n}(\%)$ & $1016(21.5)$ & $339(22.4)$ & $554(22.8)$ & $486(30.8)$ \\
\hline CESD-10 >10 2010 n (\%) & $591(15.7)$ & $200(16.8)$ & $370(19.1)$ & $298(23.2)$ \\
\hline $\begin{array}{l}\text { Odds ratio of CESD score }>10(95 \% \mathrm{Cl}) \\
\text { (adjusted)+ }\end{array}$ & 1.0 & 1.1 (0.8 to 1.4$)$ & 1.5 (1.1 to 1.9$)$ & 1.7 (1.1 to 2.4$)$ \\
\hline
\end{tabular}

Total number of participants dependent on outcome measure.

* Adjusted for alcohol consumption, BMI (interaction), physical component scores, physical activity,

+ Adjusted for meeting physical activity requirements, smoking, alcohol consumption, physical health component score and use of diuretics, laxatives or diet pills and BMI (interaction) 
Table 3: Mean weight change by weight pattern group and BMI category (95\% CI)

\begin{tabular}{|llcll}
\hline & NWC & WL & LFWC & FWC \\
Obese $\mathbf{n = 1 4 5 8}$ & $1.4(0.3$ to 2.5$)$ & $1.1(-0.06$ to 2.3$)$ & $4.5(1.7$ to 3.4$)$ & $4.3(3.6$ to 5.0$)$ \\
Overweight $\mathbf{n}=\mathbf{2 3 2 8}$ & $3.3(2.6$ to 4.0$)$ & $5.9(5.0$ to 6.8$)$ & $4.8(4.1$ to 5.6$)$ & $4.5(3.6$ to 5.3$)$ \\
Healthy weight $\mathbf{n}=\mathbf{3 6 1 8}$ & $3.6(3.1$ to 4.2$)$ & $4.6(3.8$ to 5.4$)$ & $5.1(-0.5$ to 10.6$)$ \\
Underweight $\mathbf{n}=\mathbf{1 0 8}$ & $5.7(4.0$ to 7.5$)$ & $4.6(-0.3$ to 9.6$)$ & $6.3(5.1$ to 7.5$)$ \\
\hline
\end{tabular}

NWC= non-weight cyclers, $\mathrm{WL}=$ weight losers, $\mathrm{LWC}=$ low weight cyclers, $\mathrm{FWC}=$ frequent weight cyclers Adjusted for: smoking and physical health component scores. 
Table 4: Mean difference in weight change by BMI category in reference to the $\mathrm{NWC}(95 \% \mathrm{CI})$

\begin{tabular}{|l|l|l|l|}
\hline NWC (reference group) & FWC & LFWC & WL \\
\hline Obese & $-0.6(-1.8$ to 0.6 & $3.0(1.8$ to 4.2$)$ & $0.3(-1.8$ to 1.3$)$ \\
\hline Overweight & $1.2(0.2$ to 2.1$)$ & $1.0(0.2$ to 1.8$)$ & $2.6(1.6$ to 3.6$)$ \\
\hline Healthy weight & $2.7(1.4$ to 3.9$)$ & $1.2(0.4$ to 1.9$)$ & $1.0(0.2$ to 1.7$)$ \\
\hline
\end{tabular}

NWC= non weight cyclers, $\mathrm{WL}=$ weight losers, $\mathrm{LWC}=$ low weight cyclers, $\mathrm{FWC}=$ frequent weight cyclers

Adjusted for: smoking and physical health component scores. 